2 Calvert, E. S. (1961). A comparison of two systems for avoiding collision. This Journal, 14, 379.

3 Garcia-Frias, J. (1960). Anti-collision radar sectors. This Journal, 1 3, 316.

4 Hollingdale, S. H. (196r). The mathematics of collision avoidance in two dimensions. This Journal, I 4, 243.

5 Morrel, J. S. (1961). The physics of collision at sea. This Journal, 14, 163.

6 Sadler, D. H. (1957). The mathematics of collision avoidance at sea. This Journal, 1o, 306.

\title{
Collision Avoidance in the Air
}

$$
\text { from E. P. Fairbairn }
$$

IN June $195^{8}$ the writer submitted to the Ministry of Aviation a paper, summarized below, on the avoidance of collisions in the air. The views expressed are his own and not necessarily those of the Company for which he works.

I. The rules of the air should recognize that the information available to the pilot, whether obtained by visual or 'electronic' means, is likely to be limited by the following:

(a) the pilot's 'field of view' is at most $\pm 90^{\circ}$ in azimuth and some $\pm 20^{\circ}$ in elevation relative to his aircraft heading.

(b) a collision course can be recognized, but not the heading, course or speed of the other aircraft.

2. It was shown by the simple but somewhat laborious method of plotting a number of collision courses for various angles of approach and relative speeds, that an effective and practicable manœuvre for collision avoidance was, for an aircraft which had another in its field of view, to alter course to the right. If each aircraft can see the other, both alter course; if only one can see the other, e.g. if one is overtaking the other, only that one alters course. If the alteration of course is effective at a distance of 10 times the required miss distance, e.g. at 10 miles for a miss distance of $\mathrm{I}$ mile, a course alteration of $8^{\circ}$ is sufficient in all cases, but is more than is necessary in some. The miss distance is increased if the aircraft which has the other on its right reduces speed, e.g. by climbing, and the one which has the other on its left increases speed, e.g. by diving. Even for the fastest aircraft this small change of course can be made effective with reasonable acceleration in a distance which is short compared with those suggested above.

3. From these considerations the proposed rules are:

(a) If a pilot detects another in his field of view on a collision course he should alter his course $10^{\circ}$ to the right.

(b) If the other aircraft is on his right he may with advantage decrease speed by about 5 per cent usually by climbing; if it is on his left he may increase speed similarly usually by diving.

The much more thorough analysis made by Hollingdale in 'The mathematics of collision avoidance in two dimensions' (Journal, I 4, 243) confirms the correctness of these principles.

It is considered essential to have simple and definite rules which the pilot can apply automatically in all cases, and therefore the course should never be altered to the left. If there is a doubt whether the aircraft can safely pass 'starboard-to- 
starboard', the course should still be altered to the right and the speed increased or decreased as well in accordance with the rule.

A PPI display should only show the tracks of other aircraft relative to one's own, as that is all that matters. A radial marker emanating from one's own position and adjustable in angle over the whole field of view would make it easier to decide whether there was a risk of collision. An action in accordance with the rules by either aircraft has the same effect on the trace-it bends it to the left.

These rules would apply only to the air; at sea the conditions are not the same.

\title{
Anomalous Radar Propagation
}

\author{
from G. R. Cooper \\ (Second Officer, S.S. Clan Maclennan)
}

WHILST steaming westwards at night along the coast of South Africa, echoes were received on the radar screen that gave the impression the vessel was about twelve miles off the coast. At the time, the vessel was about thirty miles S. by W. of Seal Point.

The radar set, a Decca Mk. I 2, was operating on the twenty-five mile range. It was receiving strong echoes from a sighted ship seven miles away on the port quarter. The set had been switched on to clear an unlit buoy fitted with a radar reflector. The position of the buoy was about ten miles WSW. of the vessel's position.

The echoes forming the apparent coastline were both strong and constant. The picture formed had good definition; it was not quite the same as the charted coastline, but there was sufficient resemblance to connect the two. A second line of echoes beyond the apparent coastline showed, which under normal conditions would have been a mountain range. There are several ranges of mountains along this part of the coast, some over $5000 \mathrm{ft}$ high. The displayed coastline was from four points on the starboard bow to about one point on the port quarter. The vessel was steering $26 \mathrm{I}^{\circ}$ true to pass ten miles south of Cape Agulhas. There had not been any land on the port quarter since leaving Lourenço Marques.

The vessel's course was altered to check for false echoes, but the bearing of the echoes altered the same amount. There was no sign of any rain. The sky was cloudless and visibility good. Stars were visible at very low altitudes all round the horizon. The echoes may have been due to super-refraction.

\section{The Radio Advisory Service have sent in the following comment:}

The appearance strongly suggests second-trace echoes of high land. With a p.r.f. of 1000 and with echoes observed between I 2 and 15 miles distant, the targets for second-trace echoes would be at ranges of 92 to 95 miles, and it appears that there were ranges of mountains at that distance from the ship at that time.

On the other hand, there is the continuation of the echo on to the port side. Had the ship been on steady course there would have been no land on the port side. The ship reported a strong following wind with a rough sea and moderate swell; consequently she may have been yawing considerably and, if so, echoes 